\title{
Chemical pleurodesis for malignant pleural effusion: which agent is perfect?
}

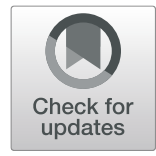

\author{
Mohamed Elshabrawy Saleh, Gehad Awad and Mohammed Sanad
}

\begin{abstract}
Background: Pleurodesis is defined as symphysis between two layers of pleura to prevent recurrence of effusion, and it is the best available treatment for recurrent effusions of incurable malignancies. An ideal agent must be highly effective, safe, inexpensive, and readily available which is yet to be identified.

The aim of this study was to assess our results of medical pleurodesis, using 3 different chemical agents: bleomycin ampoules, doxycycline capsules, povidone-iodine solution, through two different routes, chest tube and small bore indwelling catheter.

Over a period of 5 years, 104 patients with malignant recurrent pleural effusion underwent pleurodesis at our university hospital, using 3 different agents and two routes of delivery.

Results: Fifty patients were male, patients' age ranged from 22 to 74 years (57.55 \pm 9.02). Fifty-nine patients (56.7\%) had right-sided effusion, 61 patients (58.7\%) had massive effusion. All patients were dyspneic. The rout of effusion drainage and sclerosing agent instillation was chest tube in 64 patients (61.5\%) and small indwelling catheter in 40 patients. Forty-three patients received bleomycin, 36 patients received doxycycline, and 25 patients received povidone-iodine. The total success rate was $78.8 \%$.

Conclusion: Pleurodesis is a safe acceptable palliative procedure for malignant pleural effusion with not yet definite ideal agent or rout. Hence, the availability and the expense of agent are important.
\end{abstract}

Keywords: Pleurodesis, Malignant effusion, Pleural, Chemical pleurodesis, Pleurex

\section{Background}

The mainstream of malignant pleural effusion (MPE) is produced by metastatic disease: typically, bronchogenic carcinoma in men and breast cancer in females. These two cancers combined account for $50-65 \%$ of all MPE [1]. Mesothelioma is the most common type of primary pleural tumor and is associated with MPE in more than 90\% of cases. Even with the advancement in cancer treatment, the management of MPE is palliative, with median survival ranging from 3 to 12 months [1]. Patients' prognosis is extremely variable and rests on several influences (primary cancer, stage, performance

\footnotetext{
* Correspondence: mams@mans.edu.eg; mohamedsanad2008@yahoo.com Department of Cardiothoracic Surgery, Faculty of Medicine, Mansoura University, Mansoura, Egypt
}

status, and pleural fluid proteins). The LENT (pleural fluid lactate dehydrogenase, Eastern Cooperative Oncology Group performance score (ECOG), neutrophil-tolymphocyte ratio and tumor type) prognostic score was recently proposed as a tool for the accurate prediction of survival [2].

The foremost target of management of MPE is prompt and effective relief of symptoms with minimal discomfort, negligible affection of everyday activity, and cost-effectiveness. Treatment options comprise repeated thoracentesis, chest tube, or catheter drainage with pleurodesis, pleuroperitoneal shunt, pleurectomy, and thoracoscopy.

Pleurodesis is defined as the induction of symphysis between the two layers of pleura to prevent recurrence of effusion. Chemical pleurodesis is the best palliative 
treatment for recurrent effusions of end stage malignancies [3].

The ideal agent has to be highly effective, easy to administer, safe with minimal side effects, cheap, and readily available. Such agent is still a target to be identified [4].

Most of the agents used for pleurodesis cause pleural injury and inflammatory reaction with subsequent activation of the coagulation system and production of fibrogenic cytokines. All of these lead to the production of collagen that can result in a pleurodesis [5].

The aim of this study is to assess our results of medical pleurodesis for MPE, using three different chemical agents; bleomycin ampoules, doxycycline capsules, povidone-iodine solution, through two different routes, chest tube and small bore indwelling catheter.

\section{Methods}

This retrospective cohort study started in January 2011 till January 2016. We retrospectively reviewed all cases of malignant pleural effusion who were managed palliatively in our cardiothoracic surgery department at our university hospitals by pleurodesis. We compared our techniques with various agents. We did not extend the study beyond this date because pleurodesis was then performed by chest medicine department.

Approval of the institutional research board of our university was obtained. We followed the Declaration of Helsinki as regards trials on humans [6].

Our cohort study included 104 consecutive patients, 50 males and 54 females. Their ages ranged from $22-74$ years $(57.55 \pm 9.02)$.

Three sclerosing agents were used: 43 patients received bleomycin, 36 patients received doxycycline, and 25 patients received povidone-iodine.

Two routes of delivery applied were either chest tube (64 patients $(61.5 \%))$, or indwelling small catheter (40 patients (38.5\%)).
For all patients with symptomatic malignant pleural effusion, initial pleurocentesis was applied first. Many patients did not develop recurrence or died before being in need for further pleurocentesis. Other benefited from recurrent pleurocentesis as the rate of accumulation was very gradual. So, symptomatic patients with recurrent malignant pleural effusion whose general condition was reasonable and whose lungs showed no entrapment were our targets for pleurodesis. All our patients had either grade 3 or grade 4 dyspnea.

For all patients, chest X-ray (CXR) was done. Computed tomography (CT) chest was not mandatory except in cases of wide mediastinum and cases of total opacity without mediastinal shift to exclude hilar mass.

The grading of pleural effusion was conducted according to the standard grading system of free-flowing effusion proposed by Smargiassi A. et al. [7] and published in the European respiratory journal as mentioned in Table 1.

We used either chest tube 28-32 French gauge, or a 12 Fr. Pig tail catheter inserted under complete aseptic conditions using local anesthesia. We followed up the patient for evacuation of all fluid with fully inflated lung proved by CXR. The sclerosing agent of choice $(500 \mathrm{mg}$ of vibramycin capsules, bleomycin 60 $\mathrm{mg}$ ampoules, or $20 \mathrm{~mL}$ of $10 \%$ povidone-iodine) was then added to a solution of $50 \mathrm{~cm}^{3}$ of sterile saline $0.9 \%$ and $10 \mathrm{ml}$ of $2 \%$ xylocaine. The chest tube or the catheter was then clamped for $4 \mathrm{~h}$, with rotation of the patient in all possible positions for $1 \mathrm{~h}$ to ensure uniform distribution of the agent. The drain was then opened. The patient was followed up over the next few days for the success of the maneuver in achieving drainage less than $100 \mathrm{cc}$ per day and an expanded lung on CXR which enabled us to remove the tube or pig-tail catheter. For all cases with pigtail and all stable cases of chest tube, the maneuver was performed at outpatient bases.

Table 1. Radiological description of free-flowing pleural effusions as proposed by Smargiassi A. et al. [7]

\begin{tabular}{llll}
\hline Grading & Description & Landmarks & Intercostal spaces \\
\hline $\begin{array}{l}\text { Grade } 1 \\
\text { Minimum }\end{array}$ & Limited to the costophrenic sinus & Diaphragmatic dome partially evident & $\begin{array}{l}\text { Limited to costophrenic } \\
\text { sinus }\end{array}$ \\
$\begin{array}{l}\text { Grade } 2 \\
\text { Small }\end{array}$ & Lower lung lobe partially involved & Diaphragmatic dome completely evident & 1 intercostal space \\
$\begin{array}{l}\text { Grade } 3 \\
\text { Small to } \\
\text { medium }\end{array}$ & Lower lung lobe partially collapsed & $\begin{array}{l}\text { Lower lung lobe partially atelectatic, pulmonary hilum not } \\
\text { visible }\end{array}$ & $2-3$ intercostal spaces \\
Grade 4 & Lower lung lobe completely & Atelectasis of the lower lung lobe, pulmonary hilum visible. & $3-4$ intercostal spaces \\
Medium & collapsed & Atelectasis of the lower lobe, upper lung lobe partially & 4 intercostal spaces or more \\
Grade 5 & Upper lung lobe partially collapsed & atelectatic & \\
Large & Lung fully collapsed & Atelectasis of the whole lung, Hilum completely visible & \\
Massive & & &
\end{tabular}


The choice of the agent was dependent upon operator preference and the availability of the agent. Patients transferred from Oncology Department were usually prescribed bleomycin. Patients with known thyroid malfunction were not subjected to betadine. Most operators preferred chest tube thoracostomy for rapid evacuation of the effusion and better delivery of the sclerosing agent. Some preferred catheter for less pain. In case of wide mediastinum on radiographs, central bronchogenic carcinoma, trapped lung, low pressure of the effusion at time of pleurocentesis, or absent mediastinal shift despite total or near total opacity, we used catheter as from our previous experience in many of these mentioned conditions, we were unable to remove the tube and many patients developed air-fluid level and subsequent empyema.

We considered success either the ability to prevent further re-accumulation of more fluid $(<100 \mathrm{cc} /$ day) and elimination of effusion related extra dyspnea with absence of fluid reaccumulating on chest radiographs until death or loss of follow-up. The partial response entailed diminution of dyspnea related to the effusion and asymptomatic fluid re-accumulation (less than 50\% of the initial radiographic evidence of fluid) that needs no further therapy. Failure is considered when patient recurred with pleural effusion in need for intervention with the lack of success as defined above $[8,9]$.

We followed up all patients for at least 1 month; extended follow up for all these patients was problematic. Usually cases of malignant pleural effusion are end stage with expected survival for few months, and patients have other morbidities. Patients with failed pleurodesis or recurrent effusion were obliged to follow up for further management. So, lack of further follow-up signified either successful pleurodesis or patient's death.

\section{Results}

Our study included 104 patients with recurrent malignant pleural effusion, all of them were dyspneic. Fifty patients were male $(48.1 \%)$ and the remainder 54 patients were female (51.9\%). Patients' age ranged from 22 to 74 years (mean $57.55 \pm 9.02$ ).

Fifty-nine patients had a New-York heat association (NYHA) IV class of dyspnea (56.7\%), 36 patients had NYHA III class of dyspnea (34.6\%), and 9 patients (8.6\%) had only NYHA II class of dyspnea. As regards other symptoms, 32 patients had chest pain, 39 patients had cough, and 24 patients had both. The rate of pleural effusion re-accumulation was rapid in 55 patients and gradual in 49 patients.

Chest X-ray showed right side effusion in 59 patients (56.7\%) and 45 had left-sided pleural effusion. Sixty-one patients $(58.7 \%)$ had massive effusion and 72 patients (69.2\%) had mediastinal shift to the opposite side. The
Table 2. Baseline demographic data, presentation of 104 patients with malignant pleural effusion

\begin{tabular}{|c|c|c|}
\hline Characteristic & $\begin{array}{l}\text { Mean } \pm \text { SD } \\
n\end{array}$ & $\begin{array}{l}\text { Range } \\
\%\end{array}$ \\
\hline Age (mean $\pm S D$, range), years & $57.55 \pm 9.02$ & $22-74$ \\
\hline Male, $n(\%)$ & 50 & 48.1 \\
\hline Diabetes mellitus & 24 & 23.7 \\
\hline Hypertension & 57 & 54.8 \\
\hline Congestive heart failure & 13 & 12.5 \\
\hline Hepatic dysfunction & 8 & 7.7 \\
\hline Smoker & 28 & 26.9 \\
\hline Side of intervention, right, $n$ (\%) & 59 & 56.7 \\
\hline \multicolumn{3}{|l|}{ ECOG score, $n(\%)$} \\
\hline $0-2$ & 80 & 76.9 \\
\hline $3-4$ & 21 & 20.2 \\
\hline Unknown & 3 & 2.9 \\
\hline \multicolumn{3}{|l|}{ Effusion grade } \\
\hline Small (1-2) & 0 & 0 \\
\hline Moderate (3-4) & 6 & 5.8 \\
\hline Large (5) & 26 & 25 \\
\hline Massive (6) & 72 & 69.2 \\
\hline \multicolumn{3}{|l|}{ Presenting symptom* } \\
\hline Dyspnea & 104 & 100 \\
\hline Chest pain & 32 & 30.7 \\
\hline Cough & 39 & 37.5 \\
\hline Chest pain and cough & 24 & 23.1 \\
\hline \multicolumn{3}{|l|}{ Dyspnea score (NYHA) } \\
\hline NYHA ॥ & 9 & 8.7 \\
\hline NYHA III & 36 & 34.6 \\
\hline NYHA IV & 59 & 56.7 \\
\hline \multicolumn{3}{|l|}{ Pleural fluid chemistry } \\
\hline Exudate & 104 & 100 \\
\hline Mean PH & $7.14 \pm 0.22$ & $6.87-7.48$ \\
\hline $\mathrm{PH}<7.3$ & 93 & 89.4 \\
\hline $\mathrm{PH} \geq 7.3$ & 11 & 10.6 \\
\hline Glucose (mg/dl) & $73.3 \pm 25.1$ & 24-119 \\
\hline $\mathrm{LDH}(\mathrm{IU} / \mathrm{L})$ & $1493 \pm 294$ & $586-2862$ \\
\hline \multicolumn{3}{|l|}{ Pleural fluid cytology } \\
\hline WBC $(/ \mu l)$ & $624.2 \pm 58$ & $300-2216$ \\
\hline Mono (\%) & $73.4 \pm 3.6$ & $65-87$ \\
\hline Malignant (\%) & $12.3 \pm 5.2$ & $4-28$ \\
\hline $\mathrm{RBC}(/ \mu \mathrm{l})$ & $19560 \pm 58.7$ & $1400-4800$ \\
\hline
\end{tabular}

Eastern Cooperative Oncology Group (ECOG) performance status score runs from 0 to 5 , where 0 is fully active, 1 is restricted in physical strenuous activity, 2 is unable to carry out any work activities, 3 is only able to carry out limited self-care activities, 4 is completely disabled, and 5 is dead

Baseline effusion size was graded on chest radiograph immediately prior to trial intervention, using a validated grading system whereby grade 0 referred to no radiographic evidence of pleural fluid; grade 1, blunting of the costophrenic angle; grade 2 to 5 , fluid occupying less than $25 \%, 25 \%$ to $50 \%$, $51 \%$ to $75 \%$, and more than $75 \%$ of the hemithorax, respectively

*The presenting symptoms are non-mutually exclusive 
Table 3 Pathology of the primary tumor and different routes of delivery of 3 sclerosing agents for 104 cases with malignant pleural effusion

\begin{tabular}{|c|c|c|c|c|c|c|c|}
\hline \multirow[t]{2}{*}{$\begin{array}{l}\text { Pathology of the } \\
\text { primary tumor }\end{array}$} & \multicolumn{2}{|l|}{$\begin{array}{l}\text { Bleomycin } \\
(n=43)\end{array}$} & \multicolumn{2}{|l|}{$\begin{array}{l}\text { Doxycycline } \\
(n=36)\end{array}$} & \multicolumn{2}{|l|}{$\begin{array}{l}\text { Betadine } \\
(n=25)\end{array}$} & \multirow{2}{*}{$\begin{array}{l}\text { Total } \\
\\
\text { Total } \\
n(\%)\end{array}$} \\
\hline & $\begin{array}{l}\text { Chest tube and } \\
\text { bleomycin }\end{array}$ & $\begin{array}{l}\text { Pig-tail and } \\
\text { bleomycin }\end{array}$ & $\begin{array}{l}\text { Chest tube and } \\
\text { doxycycline }\end{array}$ & $\begin{array}{l}\text { Pig-tail and } \\
\text { doxycycline }\end{array}$ & $\begin{array}{l}\text { Chest tube and } \\
\text { betadine }\end{array}$ & $\begin{array}{l}\text { Pig-tail and } \\
\text { betadine }\end{array}$ & \\
\hline $\begin{array}{l}\text { Bronchogenic } \\
\text { carcinoma }\end{array}$ & 6 & 5 & 2 & 4 & 5 & 0 & $\begin{array}{l}22 \\
(21.2)\end{array}$ \\
\hline Hepatoma & 4 & 2 & 1 & 3 & 2 & 0 & $\begin{array}{l}12 \\
(11.5)\end{array}$ \\
\hline Cancer breast & 4 & 4 & 4 & 2 & 6 & 0 & $\begin{array}{l}20 \\
(19.2)\end{array}$ \\
\hline Osteosarcoma & 3 & 0 & 0 & 3 & 0 & 0 & $6(5.8)$ \\
\hline Colorectal & 3 & 0 & 0 & 3 & 3 & 0 & $9(8.7)$ \\
\hline Mesothelioma & 3 & 0 & 0 & 2 & 1 & 0 & $6(5.8)$ \\
\hline Ovarian & 3 & 0 & 1 & 2 & 2 & 0 & $8(7.7)$ \\
\hline Lymphoma & 2 & 1 & 2 & 2 & 1 & 2 & $\begin{array}{l}10 \\
(9.6)\end{array}$ \\
\hline Kidney & 1 & 0 & 0 & 2 & 0 & 0 & $3(2.9)$ \\
\hline Thymoma & 1 & 0 & 1 & 0 & 0 & 1 & $3(2.9)$ \\
\hline Esophageal & 0 & 0 & 1 & 0 & 1 & 0 & $2(1.9)$ \\
\hline Unknown primary & 0 & 1 & 0 & 1 & 1 & 0 & $3(2.9)$ \\
\hline Total n(\%) & $30(28.8)$ & $13(12.5)$ & $12(11.5)$ & $24(23.1)$ & $22(21.1)$ & $3(2.9)$ & 104 \\
\hline
\end{tabular}

demographic and clinical data of the patients are presented in Table 2. The primary tumor pathology of 104 patients is shown in Table 3.

We used three sclerosing agents. Their distribution and rate of success is shown in Tables 3 and 4.

Bleomycin, doxycycline, and betadine showed success rates of $79.1 \%, 80.6 \%$, and $76 \%$, respectively.

The route of instillation of the sclerosing agent into the pleural space was chest tube in 64 patients and small indwelling catheter in 40 patients.

Considering complications, $48.8 \%$ of bleomycin group patients suffered from pain in 9 patients (20.9\%), fever in 8 patients $(18.6 \%)$, encystation in 2 patients $(4.7 \%)$, empyema in 1 patient (2.3\%), and chest wall sinus in 1 patient (2.3\%). In doxycycline group, 23 patients had complications $(63.9 \%)$ in the form of: pain in 10 patients (27.8\%), fever in 11 patients (30.6\%), encystation in 1 (2.8\%), empyema in 1 patient (2.8\%), and chest wall sinus in 1 patient (2.8\%).

Table 4. Distribution of the sclerosing agents among our patients

\begin{tabular}{|c|c|c|c|c|c|c|c|c|}
\hline \multirow[t]{3}{*}{ Result } & \multicolumn{6}{|c|}{ Agent } & \multirow[t]{3}{*}{$x^{2}$} & \multirow[t]{3}{*}{$P$} \\
\hline & \multicolumn{2}{|c|}{$\begin{array}{l}\text { Bleomycin } \\
(n=43)\end{array}$} & \multicolumn{2}{|c|}{$\begin{array}{l}\text { Doxycycline } \\
(n=36)\end{array}$} & \multicolumn{2}{|c|}{$\begin{array}{l}\text { Betadine } \\
(n=25)\end{array}$} & & \\
\hline & No & $\%$ & No & $\%$ & No & $\%$ & & \\
\hline Failure & 9 & 20.9 & 7 & 19.4 & 6 & 24.0 & 0.186 & 0.911 \\
\hline Success & 34 & 79.1 & 29 & 80.6 & 19 & 76.0 & & \\
\hline
\end{tabular}

All cases in betadine group had complications as 21 patients $(84 \%)$ had pain, 10 patients had fever $(40 \%), 2$ patients (8\%) developed hypotension, and 1 patient developed encystation. There were no great differences between the 3 groups apart from the highly significant post maneuver pain related to betadine $(P$ value $<0.001)$. The degree of such betadine-related pain was mild to moderate and responded well to non-steroidal antiinflammatory drugs (NSAID). So, such pain was nonlimiting factor for betadine use (Table 5). The complications related to the route of delivery are mentioned in Table 6.

\section{Discussion}

In our study, the number of female patients is 54 (51.9\%) which is slightly more than males (50 patients), but excluding 20 cases of cancer breast all of them are female plus 8 cases of ovarian tumors, male gender appears to predominate.

Most malignances predominate in old age; the mean age of our patients is $57.55 \pm 9.02$ years. Dye et al. [10] reported mean age $55.8 \pm 7.7$ years.

Johnston [11] conducted a mega study on 584 specimens from 472 patients found that nearly all neoplasms had been involved the pleura. However, bronchogenic carcinoma had been the most common neoplasm, accounting for approximately one-third of all malignant effusions followed by breast carcinoma and lymphomas. Tumors less commonly associated with malignant 
Table 5 Complications related to the sclerosing agent

\begin{tabular}{|c|c|c|c|c|c|c|c|c|}
\hline \multirow[t]{3}{*}{ Complications } & \multicolumn{6}{|c|}{ Agent } & \multirow[t]{3}{*}{$x^{2}$} & \multirow[t]{3}{*}{$P$} \\
\hline & \multicolumn{2}{|c|}{$\begin{array}{l}\text { Bleomycin } \\
(n=43)\end{array}$} & \multicolumn{2}{|c|}{$\begin{array}{l}\text { Doxycycline } \\
(n=36)\end{array}$} & \multicolumn{2}{|c|}{$\begin{array}{l}\text { Betadine } \\
(n=25)\end{array}$} & & \\
\hline & $\overline{\mathrm{No}}$ & $\%$ & $\overline{\mathrm{No}}$ & $\%$ & $\overline{\mathrm{No}}$ & $\%$ & & \\
\hline Negative & 22 & 51.2 & 13 & 36.1 & 0 & 0.0 & 53.057 & $<0.001$ \\
\hline Fever and pain & 0 & 0.0 & 1 & 2.8 & 9 & 36.0 & & \\
\hline Sinus & 1 & 2.3 & 1 & 2.8 & 0 & 0.0 & & \\
\hline Pain & 9 & 20.9 & 9 & 25.0 & 12 & 48.0 & & \\
\hline Fever & 8 & 18.6 & 10 & 27.8 & 1 & 4.0 & & \\
\hline Empyema & 1 & 2.3 & 1 & 2.8 & 0 & 0.0 & & \\
\hline Loculation & 2 & 4.7 & 1 & 2.8 & 1 & 4.0 & & \\
\hline Hypotension & 0 & 0.0 & 0 & 0.0 & 2 & 8.0 & & \\
\hline
\end{tabular}

pleural effusions included ovarian and gastrointestinal carcinomas. In $5-10 \%$ of malignant effusions, no primary tumor was detected [12].

In our study bronchogenic carcinoma was the most encountered pathology (22 patients), followed by cancer breast in 20 patients (19.2\%). Hepatocellular carcinoma is a major encounter in cases of malignant pleural effusion in Egypt as it is the end result of the endemic viral hepatitis [12].

The total success rate was $78.8 \%$ (82 patients) distributed as follows: 34 patients in the bleomycin group (79.1\%), 29 patients in the doxycycline group (80.6\%), and 19 patients in the betadine group (76\%). There is no statistically significant difference between the three groups.

A study performed by Patz et al. [13] comparing doxycycline with bleomycin pleurodesis utilizing a small-bore catheter, demonstrated a success rate of $72 \%$ with bleomycin versus $79 \%$ with doxycycline.

Elayouty et al. [12] mentioned in their comparative study that bleomycin resulted in effective pleurodesis in $23 / 26$ (89\%). Povidone-iodine lead to effective pleurodesis in $22 / 25(88 \%)$. As regards pain, $68 \%$ of povidone

Table 6 Complications related to the route of delivery

\begin{tabular}{|c|c|c|c|c|c|c|}
\hline \multirow[t]{3}{*}{ Complications } & \multicolumn{4}{|c|}{ Route } & \multirow[t]{3}{*}{$x^{2}$} & \multirow[t]{3}{*}{$P$} \\
\hline & \multicolumn{2}{|c|}{$\begin{array}{l}\text { Pig-tail catheter } \\
(n=40)\end{array}$} & \multicolumn{2}{|c|}{$\begin{array}{l}\text { Chest tube } \\
(n=64)\end{array}$} & & \\
\hline & No & $\%$ & No & $\%$ & & \\
\hline Negative & 16 & 40.0 & 19 & 29.7 & 5.106 & 0.647 \\
\hline Fever and pain & 2 & 5.0 & 8 & 12.5 & & \\
\hline Sinus & 0 & 0.0 & 2 & 3.1 & & \\
\hline Pain & 12 & 30.0 & 18 & 28.1 & & \\
\hline Fever & 7 & 17.5 & 12 & 18.8 & & \\
\hline Empyema & 0 & 0.0 & 2 & 3.1 & & \\
\hline Loculation & 2 & 5.0 & 2 & 3.1 & & \\
\hline Hypotension & 1 & 2.5 & 1 & 1.6 & & \\
\hline
\end{tabular}

group developed pain versus $53 \%$ for bleomycin group. The incidence for fever was comparable being nearly one-third for each group.

Referring the success rate to the type of the primary tumor, there was no statistical difference between the various types, but 3 out of 6 patients with mesothelioma showed failure.

Shouman and colleagues [14] hypothesized that the lower rate of pleurodesis in patients with positive cytology is due to the fact that they have a larger tumor burden which covers a higher percentage of the pleural surfaces. Accordingly, the mesothelial cells are covered with the tumor and cannot respond to the pleurodesis agents in the usual manner.

Comparing the results between patients with either chest tube or small catheter, there was no significant statistical difference in success rate and occurrence of complications. But the four patients who developed either chest wall sinus (2) or empyema (2) were confined to chest tube cases.

As regards post maneuver pain, there was no significant difference between patients with either chest tube or catheter, but as regards quality of pain, patients with chest tube suffered extra pain related to the tube itself. This is not proved statistically as we did not perform the pain score analysis.

Kahrom et al. [15] from Iran in evaluated the efficacy of povidone-iodine, reported success rate $82.2 \%$ and occurrence of pain in $26.9 \%$ of their cases.

Shouman et al. [14] demonstrated that tetracycline, talc slurry, iodopovidone, and bleomycin, all resulted in comparable success rates of $80 \%, 80 \%, 66.6 \%$, and $73.3 \%$ at 30 days.

Clementsen et al. [16] studied the effect of route size, either chest tube or small catheter, on the results of pleurodesis success and recurrence of effusion. No significant difference was found. But the larger tubes caused more discomfort.

This study showed insignificant complication rates among both routes as shown in Table 4 .

Mager et al. [17] studied the effect of rolling after instillation of the agent, they found no significant effect. They recommended discontinuing this maneuver to simplify the practice.

Boland et al. [18] described the trapped lung after drainage by an air/fluid level and a lung that would not fully expand. It can cause failure simply due to the mechanical difficulty of getting the pleural surfaces apposition. Options for management this condition include pleurectomy, surgical decortication, a pleuroperitoneal shunt, and obligatory long-term drainage.

A recent Cochrane database systematic review and network meta-analysis [19] compared the results of 62 randomized trials and 3428 patients who underwent 
pleurodesis using different agents. They concluded that talc poudrage was a highly effective technique (ranked second of 16 (95\% credible interval (Cr-I) 1 to 5)) and provided evidence that it caused fewer pleurodesis failures than eight other approaches. The projected ranks of other commonly used agents were: talc slurry (fourth; 95\% Cr-I 2 to 8), mepacrine (fourth; 95\% Cr-I 1 to 10), iodine (fifth; 95\% Cr-I 1 to 12), bleomycin (eighth; 95\% Cr-I 5 to 11), and doxycyline (tenth; 95\% Cr-I 4 to 15).

Most of the secondary outcomes, including adverse events, were incoherently described by the involved studies. The reported adverse events were pain, fever, and mortality. The fever network was imprecise and showed considerable heterogeneity, but suggested placebo caused the least fever (ranked first of 11 (95\% Cr-I 1 to 7)) and mepacrine and Corynebacterium parvum (C. parvum) seemed to be connected with the most fever (ranked tenth (95\% Cr-I 6 to 11) and eleventh (95\% Cr-I 7 to 11), respectively). No differences between interventions were revealed by the network meta-analysis of the pain data. The only potential difference in mortality was recognized in the mortality network was that those receiving tetracycline appeared to have a longer survival than those receiving mitoxantrone (OR 0.16 (95\% confidence interval (CI) 0.03 to 0.72$)$ ). Indwelling pleural catheters were examined in two randomized studies, both of which reported improved breathlessness when compared to talc slurry pleurodesis, despite lower pleurodesis success rates.

The shortcomings and limitations of our study were a smaller sample that was unable to detect a significant difference between the different routes of delivery and the sclerosing agents and the lack of talc powder. There is agreement that Talc powder is the most effective agent but its side effects are dangerous as pneumonitis and acute respiratory distress syndrome, plus its unavailability in many countries including Egypt. Apart from talc powder, no one agent proved to be more efficient or less toxic up till now. The three agents we used showed similar results but doxycycline and betadine are more economic and available. We did not compare the visual analogue scores of patients due to unavailability of the pain charts in the records of these patients. A larger sample, longer study period, and larger fund are needed to determine if any statistical significance is present as regards effectiveness of different agents. This study does not stress on the association between $\mathrm{pH}$ and glucose levels in pleural fluid. Often in clinical situations, other disease-specific biomarkers would have better been used and contributed to the diagnostic procedure and may be an interesting issue for forthcoming studies.

\section{Conclusions}

Pleurodesis for recurrent malignant pleural effusion as a good palliative procedure with acceptable manageable complications. No significant differences between our agents and route used but one can consider price, availability, and patient's tolerance.

\section{Abbreviations}

MPE: Malignant pleural effusion; ECOG: Eastern Cooperative Oncology Group; CT: Computed tomography; CXR: Chest X-ray; NYHA: New York Heart Association; NSAID: Non-steroidal anti-inflammatory drugs; $\mathrm{Cr}$-I: Credible interval

\section{Acknowledgements}

This trial would not be possible without the enthusiasm and commitment of clinicians, nurses, and our patients. The authors would like to thank Dr. Walid Mohammed, the lecturer of cardiothoracic surgery at Mansoura University Faculty of Medicine, Egypt, for his efforts in writing and revising the manuscript. The authors would like to thank Dr. Hatem Beshir https://orcid.org/00000003-1366-3949 from the Department of Cardiothoracic Surgery at Mansoura University for his efforts in analyzing the data and revision of this manuscript.

\section{Ethical approval and consent to participate}

We followed the Declaration of Helsinki regarding studies on human subjects [6]. Approvals of the institutional research board of Mansoura University Faculty of Medicine was obtained (MUIRB-201-16-11). Patients were informed and signed written consents for participation in the study, operation and publishing of clinical data.

\section{Authors' contributions \\ All authors contributed equally in concepualization. MES, GA, and MS operated the cases. MES performed the literature review, obtained the medical records and participated in writing of the manuscript. GA introduced the idea of comparing different routes of delivery and participated in writing of the manuscript. MES performed literature review and wrote the manuscript with MS. MES and MS analyzed the results. All the authors have read and approved the manuscript in its currently submitted form.}

Funding

No funding was received, self-funded.

Availability of data and materials

The datasets used and/or analyzed during the current study available from the corresponding author on reasonable request.

\section{Consent for publication}

Patients were informed and signed written consents for publishing of clinical data.

\section{Competing interests}

None to declare.

Received: 12 November 2019 Accepted: 13 April 2020

Published online: 06 May 2020

\section{References}

1. Psallidas I, Kalomenidis I, Porcel JM, Robinson BW, Stathopoulos GT (2016) Malignant pleural effusion: from bench to bedside. European Respiratory Review. 25(140):189-198

2. Clive AO, Kahan BC, Hooper CE, Bhatnagar R, Morley AJ, Zahan-Evans N, Bintcliffe OJ, Boshuizen RC, Fysh ET, Tobin CL, Medford AR (2014 Dec 1) Predicting survival in malignant pleural effusion: development and validation of the LENT prognostic score. Thorax. 69(12):1098-1104

3. Estrada Saló G, Farina Ríos C, Fibla Alfara JJ, Gómez Sebastián G, Unzueta MC, León GC (2003) Spontaneous pneumothorax: Pleurodesis with an iodopovidone hydroalcoholic solution. Arch Bronconeumol. 39:171-174

4. Olivares-Torres CA, Laniado-Laborín R, Chávez-García C, León-Gastelum C, Reyes-Escamilla A, Light RW (2002) lodopovidone pleurodesis for recurrent pleural effusions. Chest. 122:581-583 
5. Pamela B (1994) M. Leigh, A. Steven. Chemical pleurodesis for malignant pleural effusions. Ann. Intern. Med. 120:56-64

6. World Medical Association. World Medical Association Declaration of Helsinki. Ethical principles for medical research involving human subjects. Bull World Health Organ. 2001;79(4):373-374.

7. Smargiassi A, Inchingolo R, Zanforlin A, Valente S, Soldati G, Corbo GM (2013) Description of free-flowing pleural effusions in medical reports after echographic assessment. Respiration. 85(5):439

8. Rafei H, Jabak S, Mina A, Tfayli A (2015) Pleurodesis in malignant pleural effusions: Outcome and predictors of success. Integr Cancer Sci Therap. 2: 216-221

9. Davies HE, Lee YG (2013) Management of malignant pleural effusions: questions that need answers. Current opinion in pulmonary medicine. 19(4): 374-379

10. Dey A, Bhuniya S, Datta Chaudhuri A, Pandit S, Saha-Dutta Chowdhury M, Sengupta A, Saha I, De P (2010) lodopovidone pleurodesis: experience of a tertiary hospital in Kolkata. Singapore Med J. 51(2):163-165

11. Johnston WW (1985) The malignant pleural effusion: a review of cytopathological diagnoses of 584 specimens from 472 consecutive patients. Cancer. 56:905-909

12. Elayouty HD, Hassan TM, Alhadad ZA (2012) Povidone- lodine versus Bleomycin Pleurodesis for Malignant Effusion in Bronchogenic Cancer Guided by Thoracic Echography. J Cancer Sci Ther. 4:182-184

13. Patz EF, McAdams HP, Erasmus JJ (1998) Sclerotherapy for malignant pleural effusions: a prospective randomized trial of bleomycin vs doxycycline with small-bore catheter drainage. Chest. 113:1305-1311

14. Shouman W, Elgazzar A, Hussien R, ElShaaray M (2012) Chemical pleurodesis for malignant pleural effusion. Egyptian Journal of Chest Diseases and Tuberculosis. 61:115-120

15. Kahrom hadi, Manouchehr Aghajanzadeh, Mohammad Reza Asgari, Mahdi Kahrom Efficacy and safety of povidone-iodine pleurodesis in malignant pleural effusions. 2017;23:53-56

16. Clementsen P, Evald T, Grode G, Hansen M, Krag JG, Faurschou P (1998) Treatment of malignant pleural effusion: pleurodesis using a small percutaneous catheter. A prospective randomized study. Respir Med. 9(2): 593-596

17. Mager HJ, Maesen B, Verzijlbergen F, Schramel F (2002) Distribution of talc suspension during treatment of malignant pleural effusion with talc pleurodesis. Lung Cancer. 36:77-81

18. Boland GW, Gazelle GS, Girard MJ (1998) Mueller PR. Asymptomatic hydropneumothorax after therapeutic thoracentesis for malignant pleural effusions Am J Roentgenol. 170:943-946

19. Clive $\mathrm{AO}$, Jones $\mathrm{HE}$, Bhatnagar R, Preston NJ, Maskell N (2016) Interventions for the management of malignant pleural effusions: a network metaanalysis. Cochrane Database of Systematic Reviews. 5

\section{Publisher's Note}

Springer Nature remains neutral with regard to jurisdictional claims in published maps and institutional affiliations.

\section{Submit your manuscript to a SpringerOpen ${ }^{\circ}$ journal and benefit from:}

- Convenient online submission

- Rigorous peer review

- Open access: articles freely available online

- High visibility within the field

- Retaining the copyright to your article

Submit your next manuscript at $\boldsymbol{\nabla}$ springeropen.com 